\title{
Empirical Analysis of the Influence of Internet Word of Mouth on Consumers' Purchase Intention
}

\author{
Jun Wang ${ }^{1, a *}$ and Liping Liu ${ }^{1, b}$ \\ ${ }^{1}$ No.3, huangjiahu west road, hongshan district, wuhan city, hubei province, China, Wuhan \\ Technology and Business University Hubei Business Service Research Development Center; \\ a1075045780@qq.com, b51441858@qq.com.
}

Keywords: IWOM; Purchase intention; Network consumers

\begin{abstract}
In this paper, through the questionnaire survey, an empirical analysis of the influence of Internet word of mouth (IWOM) on college students' purchase intention for mobile phones is undergone. SPSS software is used for reliability, validity, correlation and regression analysis. Through the analysis on the data collected from questionnaires, it is concluded that the three dimensions of IWOM, i.e. quantity, quality and professionalism, may have an influence on the purchase intention of consumers, while the timeliness of IWOM has no obvious influence on the purchase intention.

In the era of rapid development of the Internet, more and more consumers are favoring in searching product information and evaluation through the network before purchasing the products, IWOM is playing a strong role for consumers' purchase intention and enterprises' marketing. In this paper, the college students are selected as study subjects, through the empirical analysis of the influence of IWOM on consumers' purchasing intention, the impact of IWOM on their purchasing decisions are also studied.
\end{abstract}

\section{The Relevant Theoretical Basis of IWOM and Purchase Intention}

IWOM. In this paper, Dong Dahai's definition of IWOM is applied that IWOM refers to a kind of bidirectionally interactive and non-commercial communication between consumers with strong relationships via the text on the medium of Internet [1]. It can be seen that the definition of IWOM includes the following four aspects: first, IWOM information contains products, services and brands, etc.; second, IWOM has its positive and negative aspects; third, IWOM will affect consumers' purchase decision and purchasing determination to varying degrees; fourth, the IWOM mainly conveys consumers' evaluation on products, services and brands through the Internet platform[2].

Purchase Intention. The purchase intention is the subjective tendency of consumers to choose a brand or product, and the purchase intention represents the subjective probability of consumers buying a product or service [3].

Characteristics of IWOM. The characteristics of IWOM mainly include the following four aspects: the quality of IWOM information, the quantity of IWOM, the form of IWOM and the timeliness of IWOM [4].

\section{Model Construction and Research Hypotheses}

Model Construction. According to the summary of literatures, this paper puts forward and constructs the model of the influence of the IWOM on the purchase intention of the consumers from the aspects of the quality of IWOM information, the quantity of IWOM, the professionalism of IWOM and the timeliness of IWOM. 


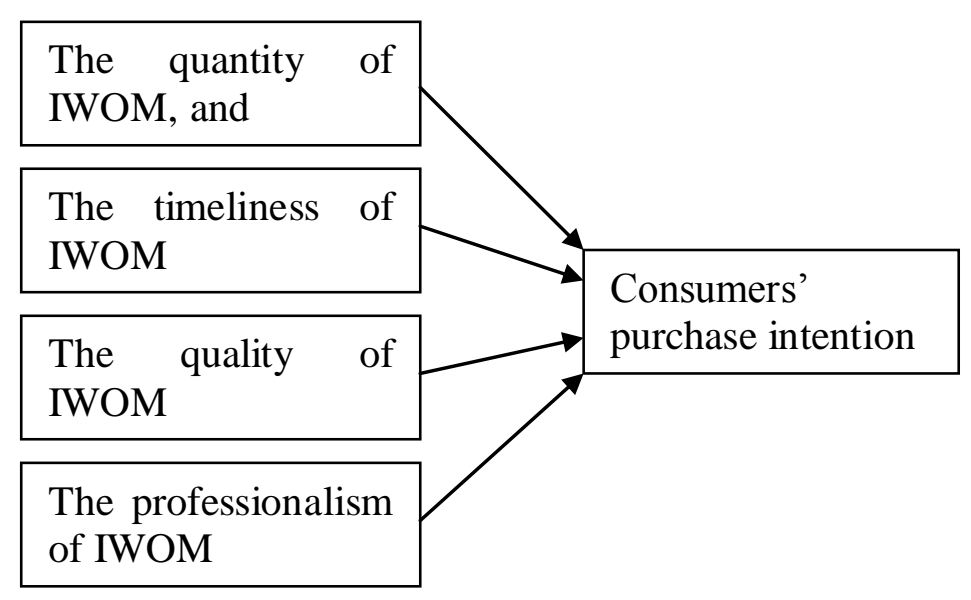

Fig. 1 Model construction

Research Hypotheses. The growing quantity of IWOM information has made consumers gain a more comprehensive and intuitive understanding of products and services. Usually, people are more inclined to trust what most people trust. Whether the majority of IWOM information with same views will have an impact on the purchase intention of consumers still needs to be verified by research. Therefore, this paper proposed hypothesis 1 :

H1: The quantity of IWOM has a significant positive correlation with consumers' purchase intention.

The timeliness of IWOM refers to the time span between the date when a consumer buys a product and a service and the date when this consumer publishes the related information on the web[5]. Through the investigation, the author found that the timeliness of the IWOM is also an important reference to consumers' purchase intention, this paper will do further research. Therefore, this paper put forward hypothesis 2:

$\mathrm{H} 2$ : The timeliness of IWOM has a significant positive correlation with consumers' purchase intention.

Text, picture and video and form of IWOM will be more logical than the traditional word of mouth and can lead to higher trust. As the IWOM is anonymously released, so only those comments which possess a high degree of correlation with the product and are objective and useful can make consumers convinced. Therefore, this paper put forward hypothesis 3:

H3: IWOM's information quality has a significant positive correlation with consumers' purchase intention.

Communication theory holds that the psychological activity and behavior of the receivers of the information can be affected by the characteristics of the information communicator[6]. Communicator's characteristics mainly refer to the ability of the receiver to perceive the communicator, that is, the degree of professionalism. Therefore, this paper put forward hypothesis 4:

H4: IWOM professionalism has a positive correlation with consumers' purchase intention.

\section{Questionnaire Design}

Questionnaire Design. The variables studied in this paper include the quantity of IWOM, the timeliness of IWOM, the information quality of IWOM and the professionalism of IWOM. According to the relevant theories of literatures, these variables are defined and the measurement scale is described.

The quantity of IWOM. There are three components for studying the quantity of IWOM: the product has a lot of comments; the comment to a product is agreed and supported by most people; one particular issue about the product is supported by most people.

The timeliness of IWOM. There are three components for evaluating the timeliness of IWOM: the evaluation of the product is up-to-date; the product's evaluation can reflect the latest 
developments in the product; consumers can reflect and evaluate the feelings on the product in time.

The information quality of IWOM. There are three components for the information quality of IWOM: the evaluation information of the product is mostly objective; the evaluation information of the product is easy to understand; the evaluation of the product is mostly credible.

The professionalism of IWOM. There are three professional components for the professionalism of the IWOM: the publisher of the product information is an expert in the field; the publisher of the product information is a person with rich buying or using experience; the publisher of the product information has a good social reputation.

Selection of Subjects. The subjects of this study are students who aged 20-25 years old, with education level of college or above. The reasons for the selection of college students as the main research subjects are as follows: the overall quality of college students is high and they are one of the main forces of mobile phone products consumption, and college students often access the network, and most college students will search for relevant information on the network platform before the purchase of mobile products.

Questionnaire are issued mainly in two forms: first, paper questionnaires, the author directly sent the questionnaires to the hands of subjects, and the questionnaires were collected immediately after the completion of answering; second, network questionnaires, the questionnaires were published on the professional survey sites in the form of electronic files and were sent to the subjects, then the questionnaires were collected within a specified time. The questionnaires were issued in 200 copies, including 185 effective questionnaires and with an effective proportion of $92.5 \%$.

\section{Data Analysis}

Descriptive Statistical Analysis. Data statistics were conducted according to the collected questionnaires, and the frequencies of gender, education, age and online time length were analyzed in samples of college students, as shown in Table 1.

Table 1 Statistical characteristics table of samples

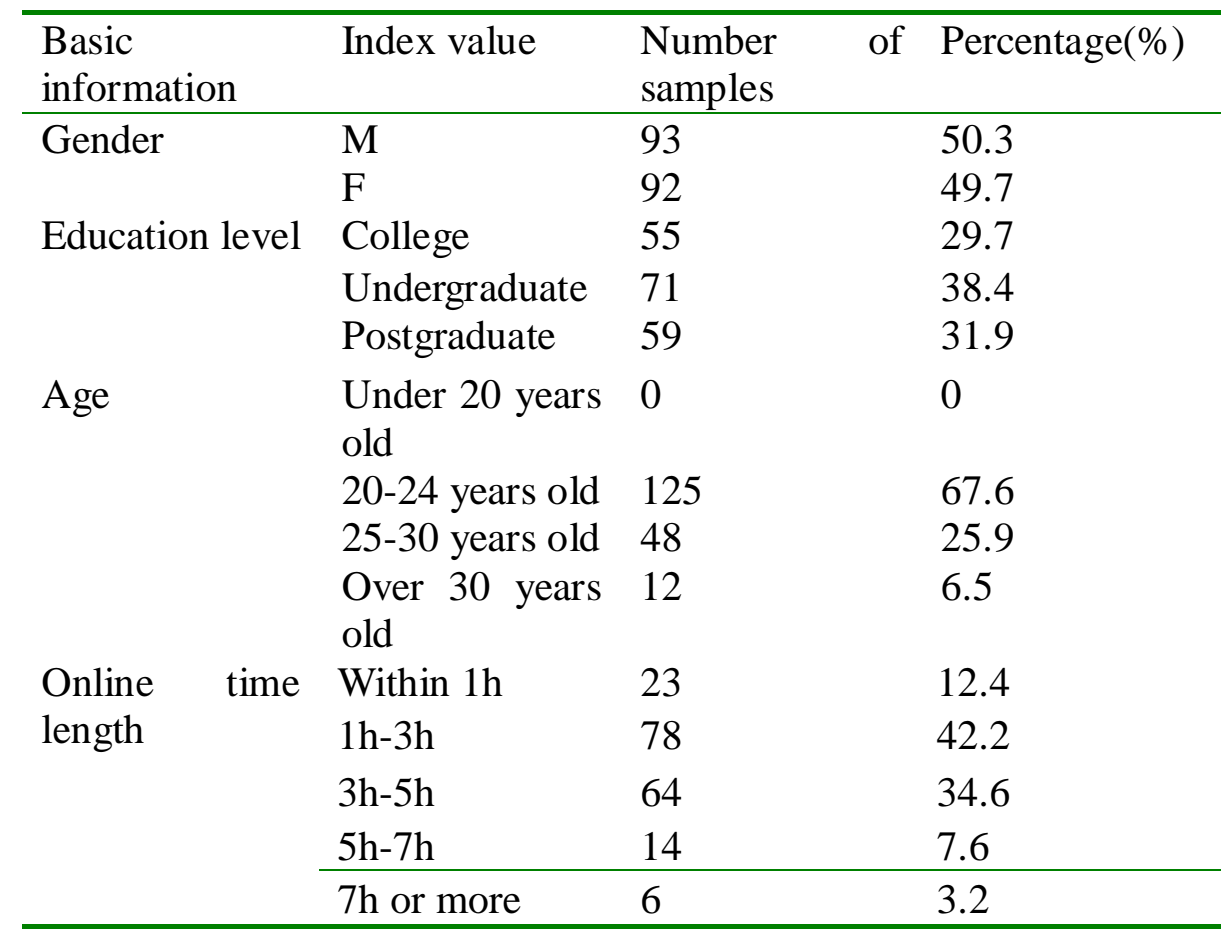

Reliability Analysis. The definition of reliability is the consistency or stability of the measurement results, that is, the degree of consistency of the results obtained if the same group undergoes different measurements [7]. In general, for reliability, the Cronbach's $\alpha$ value is used as a judgment coefficient, if the value is greater than 0.7 , then it has a high degree of reliability; if the value is 
between 0.7 to 0.35 , then the reliability is acceptable; if the value is less than 0.35 , then it has a low degree of reliability, the data do not have reference value. Scale data for reliability analysis is shown in Table 2.

Table 2 Reliability analysis

\begin{tabular}{llllll}
\hline Variables & $\begin{array}{l}\text { Number of } \\
\text { test items }\end{array}$ & $\begin{array}{l}\text { Cronbach's } \\
\text { value }\end{array}$ & $\begin{array}{l}\text { Total } \\
\text { number } \\
\text { test items }\end{array}$ & $\begin{array}{l}\text { Cronbach's } \\
\text { of }\end{array}$ \\
$\begin{array}{l}\text { The quantity of } \\
\text { IWOM }\end{array}$ & 3 & 0.801 & 12 & 0.893 \\
$\begin{array}{l}\text { The timeliness of } \\
\text { IWOM }\end{array}$ & 3 & 0.783 & & \\
$\begin{array}{l}\text { The quality of } \\
\text { IWOM }\end{array}$ & 3 & 0.841 & & \\
$\begin{array}{l}\text { The } \\
\text { professionalism } \\
\text { of IWOM }\end{array}$ & 3 & 0.881 & & \\
\hline
\end{tabular}

From the above table, it can be seen that, based on the measurements on various aspects of IWOM, Cronbach's $\alpha$ values are higher than the reliability coefficient of 0.7 , indicating that the total reliability of all sub-projects is valid and appropriate and the variables of the questionnaire have high reliability and good internal consistency.

Validity Analysis. Validity refers to the degree of each test item of variables for effective measurement of variable trait, and the validity is composed of two parts: the content validity and the structural validity[13]. The validity of the content in this paper is obtained based on summary and finishing on a lot of scholars' theories for IWOM and purchase intention and the actual evaluation of the shopping site, so the content validity is relatively at a high level. The structural validity can be tested using the Bartlett's spherical test. If the KMO value $>0.7$, it indicates the structure of the questionnaire is relatively good and the collected data can be used for factorial analysis. Usually, before the factor analysis, the data collected should be tested by the KMO value and the Bartlett's spherical test in order to figure out whether the data are suitable for factor analysis, as shown in Table 3.

Table 3 KMO and Bartlett's test

\begin{tabular}{lll}
\hline KMO sample measure test & 0.803 \\
& Chi square approximation & 1288.132 \\
Bartlett's & DF value & 130 \\
\cline { 2 - 3 } spherical test & Sig & 0.000 \\
\hline
\end{tabular}

Table 4-3 showed that the KMO value is 0.803 and greater than 0.7 , indicating that the data conform to the criteria for factor analysis. The significance Sig value was 0.000 and less than 0.001 , indicating that the sample conforms to the conditions for factor analysis. In the factor analysis, the principal component analysis was used to obtain the rotation component matrix of the questionnaire scale, as shown in Table 4. 
Table 4 Rotation component matrix table

\begin{tabular}{|c|c|c|c|c|c|}
\hline Serial & Factors & Ingred & & & \\
\hline No. & & 1 & 2 & 3 & 4 \\
\hline 1 & The product has a lot of comments & 0.811 & 0.812 & 0.421 & 0.212 \\
\hline 2 & $\begin{array}{l}\text { The comment to a product is agreed and } \\
\text { supported by most people }\end{array}$ & 0.734 & 0.734 & 0.177 & 0.041 \\
\hline 3 & $\begin{array}{l}\text { One particular issue about the product is } \\
\text { supported by most people }\end{array}$ & 0.707 & 0.254 & 0.083 & 0.081 \\
\hline 4 & $\begin{array}{l}\text { The evaluation of the product is } \\
\text { up-to-date }\end{array}$ & 0.122 & 0.822 & 0.211 & 0.232 \\
\hline 5 & $\begin{array}{l}\text { The product's evaluation can reflect the } \\
\text { latest developments in the product }\end{array}$ & 0.142 & 0.768 & 0.073 & 0.153 \\
\hline 6 & $\begin{array}{l}\text { Consumers can reflect and evaluate the } \\
\text { feelings on the product in time }\end{array}$ & 0.123 & 0.664 & -0.007 & 0.148 \\
\hline 7 & $\begin{array}{l}\text { The evaluation information of the } \\
\text { product is mostly objective }\end{array}$ & 0.178 & 0.092 & 0.675 & 0.123 \\
\hline 8 & $\begin{array}{l}\text { The evaluation information of the } \\
\text { product is easy to understand }\end{array}$ & 0.125 & 0.145 & 0.602 & 0.132 \\
\hline 9 & $\begin{array}{l}\text { The evaluation of the product is mostly } \\
\text { credible }\end{array}$ & 0.159 & 0.273 & 0.664 & 0.086 \\
\hline 10 & $\begin{array}{l}\text { The publisher of the product } \\
\text { information is an expert in the field }\end{array}$ & 0.095 & 0.143 & -0.009 & 0.842 \\
\hline 11 & $\begin{array}{l}\text { The publisher of the product } \\
\text { information is a person with rich buying } \\
\text { or using experience }\end{array}$ & 0.114 & 0.152 & 0.137 & 0.643 \\
\hline 12 & $\begin{array}{l}\text { The publisher of the product } \\
\text { information has a good social reputation }\end{array}$ & 0.141 & 0.175 & 0.123 & 0.674 \\
\hline
\end{tabular}

As shown in Table 4-4, after adopting the suitability test for the factor, the principal component analysis method is used to extract the common factors and the maximum variance orthogonal rotation method is used to extract the factors with a factor eigenvalue greater than 1 , in addition, the maximum convergence iteration is 25 . As shown in the above table, through test the difference in the overall variance of the four factors is $72.64 \%$, which are the quantity, quality, timeliness and professionalism of IWOM. It can be seen from the table that the variable design in the model and the factors after the extraction are consistent, and through the detection on different questions of each factor, it can be seen that the value of each item are in line with the requirements of the study.

Correlation Analysis and Verification. Measuring the degree of interrelationship between the two items is the main purpose of the correlation analysis, which covers a wide range, but does not mean causality test. The main measurement criteria used in this paper is Pearson coefficient. If it is positive, indicating that there is a positive correlation between the two items, on the contrary, there is a negative correlation. By using SPSS for analysis, the following results are shown in Table 5. 
Table 5 Pearson correlation coefficient analysis

Influencing

factors
The degree of influence on the purchase intention

Person

correlation

coefficient

$0.733 * *$

0.000

IWOM

The timeliness

of IWOM

$0.369 * *$

0.001

The quality of

$0.619 * *$

0.000

IWOM

The

$0.642 * *$

0.000

professionalism

of IWOM

(Note: $* *$ indicates significant correlation at the level lower than 0.01 )

Through the table, it can be seen that the quantity, timeliness, quality, professionalism of IWOM all have significances at a level below 0.01, that is, this analysis is valuable. But the Person correlation coefficients of four dimensions are different, indicating their positive correlation degrees. The quantity of IWOM, the quality of IWOM and the professionalism of IWOM are significantly correlated to purchase intention, while the significance of timeliness of IWOM is weaker.

Regression Analysis and Verification. Through the correlation analysis, it can determine that there are correlations between two items, but whether it is a causal relationship can only be determined through regression analysis, regression analysis refers to analysis on the independent variables and the dependent variables. This paper intends to analyze the absence or presence of the causal relationship between the quality, quantity, timeliness or professionalism and consumers' purchase intention. Where $\mathrm{R}$ represents the goodness of fit, its value is between 0 and 1 , and the larger the value is, the better the regression is. The Sig value represents the significance coefficient in the regression relation. When $\mathrm{Sig}>0.05$, it indicates the regression analysis of the model is meaningless. If Sig $=<0.05$, the test is meaningful. They are shown in Table 6 and 7 .

Table 6 Regression analysis Table 1

\begin{tabular}{lllllll}
\hline Model & $\mathrm{R}$ & $\mathrm{R}^{2}$ & $\begin{array}{l}\text { Adjusted } \\
\mathrm{R}^{2}\end{array}$ & $\begin{array}{l}\text { Estimated } \\
\text { standard error }\end{array}$ & $\begin{array}{l}\mathrm{F} \text { test } \\
\text { value }\end{array}$ & $\begin{array}{l}\text { Significance } \\
\text { Sig. }\end{array}$ \\
\hline $\begin{array}{l}\text { The } \\
\text { degree }\end{array}$ & 0.608 & 0.369 & 0.357 & .802 & 26.964 & 0.000 \\
of & & & & & & \\
influence & & & & & & \\
on \\
purchase \\
intention
\end{tabular}


Table 7 Regression analysis Table 2

\begin{tabular}{lllll} 
Model & \multicolumn{2}{l}{$\begin{array}{l}\text { Non-standardized } \\
\text { coefficient }\end{array}$} & $\begin{array}{l}\text { Standard } \\
\text { coefficient }\end{array}$ & Sig \\
& B & $\begin{array}{l}\text { Standard } \\
\text { error }\end{array}$ & $\beta$ & \\
& 2.194 & 0.216 & & \\
Constant & 0.324 & 0.037 & 0.346 & 0.000 \\
$\begin{array}{l}\text { The quantity of } \\
\text { IWOM }\end{array}$ & 0.031 & 0.086 & 0.478 \\
$\begin{array}{l}\text { The timeliness } \\
\text { of IWOM }\end{array}$ & 0.075 & 0.031 & 0.000 \\
$\begin{array}{l}\text { The quality of } \\
\text { IWOM }\end{array}$ & 0.274 & 0.037 & 0.327 & \\
\hline $\begin{array}{l}\text { The } \\
\text { professionalism } \\
\text { of IWOM }\end{array}$ & 0.378 & 0.034 & 0.312 & 0.000 \\
\hline
\end{tabular}

From the analysis results, the timeliness of IWOM is 0.478 and greater than 0.05 , which indicates that the causal relationship between the timeliness of IWOM and the purchase intention of is not significant. The standardization coefficients of the quantity of IWOM, the timeliness of IWOM, the quality of IWOM and the professionalism of IWOM are $0.346,0.086,0.327$ and 0.312 , indicating that the quantity of IWOM has the greatest impact on the purchase intention of consumers, followed by the quality of IWOM and the professionalism of IWOM, while the timeliness of IWOM has the least impact.

Based on all the above analyses, the verification results of hypotheses are summarized in Table 8.

Table 8 Verification results of hypotheses

\begin{tabular}{llll}
\hline Items & Content & & Conclusion \\
1 & $\begin{array}{l}\text { The quantity of IWOM has a } \\
\text { significant positive positive } \\
\text { correlation with the consumer's } \\
\text { purchase intention }\end{array}$ & \\
& $\begin{array}{l}\text { The timeliness of IWOM has a Invalid } \\
\text { significant positive positive } \\
\text { correlation with the consumer's }\end{array}$ \\
& $\begin{array}{l}\text { purchase intention } \\
\text { The quality of IWOM has a significant Valid } \\
\text { positive positive correlation with the } \\
\text { consumer's purchase intention }\end{array}$ \\
\hline 4 & $\begin{array}{l}\text { The professionalism of IWOM has a Valid } \\
\text { significant positive positive } \\
\text { correlation with the consumer's } \\
\text { purchase intention }\end{array}$
\end{tabular}




\section{Conclusion}

In this paper, the influence of IWOM on the purchase intention of students for mobile phones is selected as case for study, through the form of questionnaire, all data were collected and analyzed by SPSS software, the following conclusions were obtained:

First, the quantity of IWOM has a positive correlation with consumer's purchase intention, the quantity of IWOM has a very important influence on consumer's purchase intention.

Second, the timeliness of IWOM. From the results of the data analysis of this study, the data can not fully explain that the timeliness of IWOM has a positive correlation with consumer's purchase intention. However, the timeliness of IWOM for the enterprises which just initially enter into the network platform is still very important, because such enterprises always lack information about IWOM, these enterprises should use various measures to encourage consumers to give comments on products as soon as possible.

Third, the quantity of IWOM has a positive correlation with consumer's purchase intention. The higher the quality of IWOM is, the greater the consumer's purchase intention is.

Fourth, the professionalism of IWOM has a positive correlation with consumer's purchase intention. The higher the professionalism of IWOM is, the greater the consumer's purchase intention is.

\section{References}

[1] D.H. Dong, Y. Liu. Chinese Journal of Management,(2012) NO.27 (3), p428-436. (in Chinese)

[2] J.Y. Feng,W.S. Mu and Z.T. Fu. Modern Management , (2006) NO.40 (11), p90-99. (in Chinese)

[3] J.J. Zhang. Study on the influential factors of re-dissemination of IWOM in network environment (Zhejiang University, China,2007). (in Chinese)

[4] Q.Q. Li. Study on the influential factors of IWOM on college students' brand attitudes (MS. South China University of Technology, China 2010). (in Chinese)

[5] Y.W. Zheng. The impact mechanism of IWOM on consumption decision-making (Shanghai Jiaotong University, China,2011). (in Chinese)

[6] S.S. Lin, J.H. Tang. Marketing Review, (2010) NO.7 (2), p187-208. (in Chinese)

[7] M.L. Wu. SPSS statistical application practice (China Railway Publishing House, China, 2000), p14-21. 